\title{
Multi-decadal river flow variations in France
}

\author{
J. Boé ${ }^{1}$ and F. Habets ${ }^{2}$ \\ ${ }^{1}$ Sciences de l'Univers au CERFACS, URA1875, CNRS/CERFACS, Toulouse, France \\ ${ }^{2}$ UMR 7619 METIS, CNRS UPMC, Paris, France \\ Correspondence to: J. Boé (boe@cerfacs.fr)
}

Received: 28 August 2013 - Published in Hydrol. Earth Syst. Sci. Discuss.: 26 September 2013

Revised: - Accepted: 30 December 2013 - Published: 19 February 2014

\begin{abstract}
In this article, multi-decadal variations in the French hydroclimate are investigated, with a specific focus on river flows. Based on long observed series, it is shown that river flows in France generally exhibit large multi-decadal variations in the instrumental period (defined in this study as the period from the late 19th century to the present), especially in spring. Differences of means between $21 \mathrm{yr}$ periods of the 20th century as large as $40 \%$ are indeed found for many gauging stations. Multi-decadal spring river flow variations are associated with variations in spring precipitation and temperature. These multi-decadal variations in precipitation are themselves found to be driven by large-scale atmospheric circulation, more precisely by a multi-decadal oscillation in a sea level pressure dipole between western Europe and the eastern Atlantic. It is suggested that the Atlantic Multidecadal Variability, the main mode of multidecadal variability in the North Atlantic-Europe sector, controls those variations in large-scale circulation and is therefore the main ultimate driver of multi-decadal variations in spring river flows. Potential multi-decadal variations in river flows in other seasons, and in particular summer, are also noted. As they are not associated with significant surface climate anomalies (i.e. temperature, precipitation) in summer, other mechanisms are investigated based on hydrological simulations. The impact of climate variations in spring on summer soil moisture, and the impact of soil moisture in summer on the runoff-to-precipitation ratio, could potentially play a role in multi-decadal summer river flow variations. The large amplitude of the multi-decadal variations in French river flows suggests that internal variability may play a very important role in the evolution of river flows during the next decades, potentially temporarily limiting, reversing or seriously aggravating the long-term impacts of anthropogenic climate change.
\end{abstract}

\section{Introduction}

The role of internal low-frequency variations in the evolution of the climate system has recently received increasing attention, stemming from the societal need for relevant climate information on the next few decades for planning and adaptation in the context of climate change. Internal low-frequency variations can indeed temporarily either aggravate, moderate or even reverse the long-term impact of global warming. Current climate projections suggest that internal lowfrequency variability is a major source of uncertainties on the coming decades (Hawkins and Sutton, 2009; Deser et al., 2010, 2012). For example, regarding precipitation change over France in the middle of the 21st century, uncertainties related to internal variability may be as large as uncertainties due to climate models (Terray and Boé, 2013).

The realism of those estimations of the impact of internal variability in future projections depends on the ability of climate models to correctly simulate low-frequency internal modes of variability. Unfortunately, current models generally present some moderate deficiencies in capturing the exact spatio-temporal characteristics of the observed lowfrequency variations in the North Atlantic Ocean, and more serious difficulties in correctly capturing the associated hydroclimate impacts over land (Kavvada et al., 2013). This issue regarding hydroclimate variations is especially problematic since, due to the multiplicity of the uses for water and the tensions that often already exist between demand and resources, low-frequency fluctuations in continental hydroclimate, and in particular river flows, may have particularly serious impacts for society.

Therefore, some progress needs to be made towards better characterization and understanding of the low-frequency internal variations in the climate system, not only in the ocean, 
which plays a central role in their existence, but also how they impact continental hydroclimate. Despite the shortness of the instrumental record when dealing with multi-decadal variations, and despite the fact that observed variations are always the result of both internal and forced components, and therefore do not allow for readily disentangling the contributions of both sources of variability, observational studies remain crucial in such a context.

The main mode of multi-decadal variability in the North Atlantic-Europe sector is the Atlantic Multidecadal Variability (AMV, also known as Atlantic Multidecadal Oscillation; Kerr, 2000). The AMV is characterized by basin-wide variations in the North Atlantic sea surface temperature on multidecadal timescales (60-100 yr in the instrumental period (defined in this study as the period from the late 19th century to the present); e.g. Schlesinger and Ramankutty, 1994; Kerr, 2000). Based on climate simulations, it is generally hypothesized that buoyancy-driven variations of the Atlantic Meridional Overturning Circulation (AMOC) intrinsic to the climate system largely drive the AMV (Delworth and Mann, 2000). However, whether the AMV is mainly an internal mode of variability or is to a large extent forced by external forcing remains somewhat controversial. On the one hand, palaeoclimate data suggest that AMV-like variability is not limited to the instrumental period (e.g. Gray et al., 2004). Moreover, pre-industrial control coupled climate simulations generally exhibit modes of variability whose spatio-temporal characteristics are relatively similar to the observed AMV (e.g. Knight et al., 2005). On the other hand, other studies point toward a potentially important role of climate forcing on observed multi-decadal variations in the North Atlantic in the instrumental period, such as volcanic eruption (Otterå et al., 2010) or aerosols (Booth et al., 2012).

Independent of the driving mechanism(s), which are not the object of our study, the results of previous studies suggest a potential impact of the AMV on continental hydrological cycle over France, as is the case in the USA (Endfield et al., 2001). Indeed, statistical relationships between drought severity for some French rivers and averaged North Atlantic sea surface temperatures (SST) have been found (Giuntoli et al., 2013) and may be related to multi-decadal variations in SST. Regarding multi-decadal timescales more specifically, in the instrumental period, positive phases of the AMV are significantly associated with larger temperature over France in spring and to a lesser extent in summer and with below average spring precipitation (Sutton and Hodson, 2005; Sutton and Dong, 2012). Physically, those changes in the surface climate are expected to lead to multi-decadal river flow anomalies. Additionally, multi-decadal variations in precipitation extremes have been found in Europe, including France, with potential links with the AMV (Willems, 2013a, b).

The objective of the present work is to characterize the multi-decadal variations in the French river flows in the instrumental period and to understand the physical mechanisms responsible for those variations.
After a description of the data, models and methods used (Sect. 2), multi-decadal variations in French rivers flows and surface climate are characterized based on long observed series (Sect. 3). In particular, large multi-decadal variations in spring river flows and precipitation are described. The driving mechanisms of river flow variations in spring are investigated in Sect. 4. The importance of variations in large-scale circulation in modulating precipitation in France, themselves likely driven by the AMV, is particularly illustrated. Section 5 is dedicated to the study of potential multi-decadal variations observed in summer river flows that cannot be explained by variations in summer precipitation. The role of soil moisture in particular is investigated based on hydrological modelling. Finally, the main results of this study are discussed in Sect. 6 and conclusions are given in Sect. 7.

\section{Data, models and methods}

\subsection{River flow data}

Daily river flows at 38 gauging stations across France are analysed in this study. Data have been extracted from the national HYDRO database (http://www.hydro.eaufrance.fr/). These stations have been selected so that measurements cover at least $70 \mathrm{yr}$. Series at all selected gauging stations start before 1940, and their median length is $94 \mathrm{yr}$.

Gauging stations where too many values are missing have been discarded. When less than three-quarters of daily values are available during a given civil year (season), the corresponding annual (seasonal) mean is considered as missing. At most, $6 \%$ of years are missing for the selected stations with that definition. The missing values as previously defined in the selected series are filled by the corresponding long-term climatological average. This approach has been chosen in order to be able to low-pass-filter the river flow series (see Sect. 2.5) without introducing high-frequency noise or/and artificially enhancing low-frequency variability. This very crude infilling approach is conservative in the context of this study. Indeed, more sophisticated methods (e.g. temporal interpolation based on neighbour years, etc.) might artificially enhance low-frequency variations.

The location of the gauging stations and the length of the corresponding river flow series are shown in Fig. 1a. Stations are not uniformly distributed over France, as there are very few stations in the north, while central France is well covered. For the majority of gauging stations the catchment size is smaller than $1000 \mathrm{~km}^{2}$. Only four stations exceed $50000 \mathrm{~km}^{2}$ (Fig. 2a).

Metadata indicate that river flows are directly influenced by human activity at some of the selected gauging stations (e.g. dams or water intakes). It has been decided not to discard those stations a priori because they may still provide valuable information, so they have instead been flagged for the interpretation of the results (Fig. 1a). Note also that this 

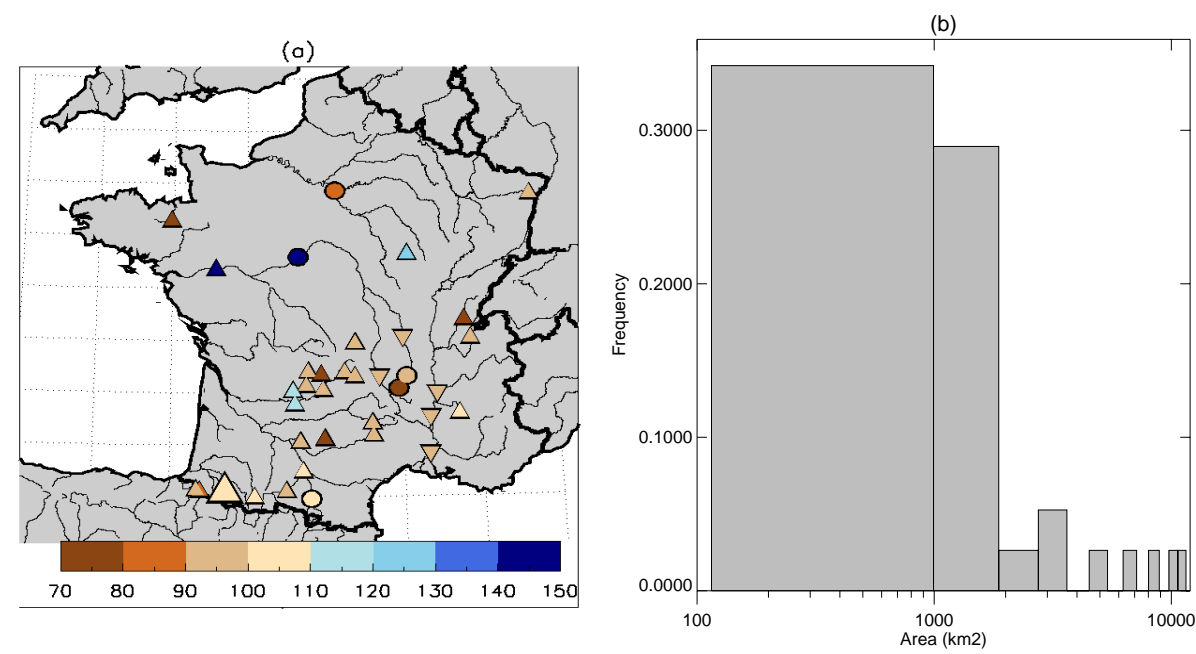

Fig. 1. (a) Location of the gauging stations whose data are analysed in this study. The length of the record in years is given by the colour scale. The symbols give an indication of the potential direct human influence on the hydrological regime for each station. Upward triangle: no or little influence ( $74 \%$ of stations); circle: strong influence (13\% of stations); downward triangle: strong influence on low flows (13\% of stations). The large triangle in southwestern France corresponds to the Gave d'Ossau at Oloron-Sainte-Marie (see Fig. 2.). (b) Histogram (in relative frequency, no unit) of the catchment sizes corresponding to the gauging stations. Note that the $x$ axis is logarithmic.

data set is not homogenized and therefore stations in the "no or little influence" categories are not necessarily free of other artefacts (e.g. change in measurement). Therefore, one must be cautious in the interpretation of variations at any particular station, and the focus of this study is on large-scale patterns of coherent variations.

\subsection{Long precipitation and temperature data set}

In order to study the local climate variations concomitant with river flow variations in France, different precipitation and temperature data sets are considered. For precipitation, a large set of monthly homogenized time series aggregated by department to form 51 time series that sample a large portion of France, from Météo-France, is used (HPS - homogenized precipitation series; Moisselin et al., 2002). HPS data are available from 1900 to 2000. In this work, HPS is seen as the reference data set for multi-decadal variations in precipitation.

Unfortunately, this high-quality data set does not cover the beginning of the 21 st century. A second precipitation data set, that covers this period, from the Global Precipitation Climatology Centre (GPCC), is also used (full data reanalysis from 1901 to 2011; Rudolf and Schneider, 2005). This monthly gridded data set with a resolution of $0.5^{\circ}$ is not adjusted to study long-term variability. Most notably, the stations used to estimate precipitation in each grid cell vary in time. Using GPCC in this study therefore requires caution and it is a priori less suitable than HPS to study low-frequency variability.

Precipitation from the 20th Century Reanalysis project (20CR in the following; Compo et al., 2011) is also analysed. This data set covers the $1871-2010$ period, with a daily time step and a spatial resolution of roughly $2^{\circ} \times 2^{\circ}$. The only observation assimilated by the 20CR system is surface pressure (SP). Observed sea surface temperature, sea ice cover, time-varying global mean $\mathrm{CO}_{2}$ and volcanic aerosol concentration, as well as incoming solar radiation, are used as forcing in the atmospheric model of the 20CR system. Some caveats are associated with $20 \mathrm{CR}$ data. SP observations are very sparse at the beginning of the period (and well within the 20th century for some areas), and therefore the accuracy of the reanalysis is necessarily more limited then. As only SP is assimilated, this reanalysis cannot in theory have the same level of accuracy as more classical reanalyses for variables that are not strongly controlled by large-scale circulation. On the other hand, temporal inconsistencies associated with changes in instruments (new satellites, etc.) are avoided in 20CR. However, the change over time of the number of SP observations assimilated may still result in artificial temporal variations (Krueger et al., 2013). One cannot expect the quality of 20CR precipitation to be on par with observed data sets. However, it remains interesting for our study as it is an estimation of precipitation that is completely independent of HPS and GPCC. The comparison of the three precipitation data sets based on different data and/or statistical treatment will be useful in assessing the robustness of our results.

For temperature, monthly homogenized series at different stations over France from Météo-France are used in this study (Moisselin et al., 2002).

\subsection{Large-scale climate}

In order to study the link of hydroclimate variations in France with large-scale circulation, sea level pressure (SLP) has 
(a)

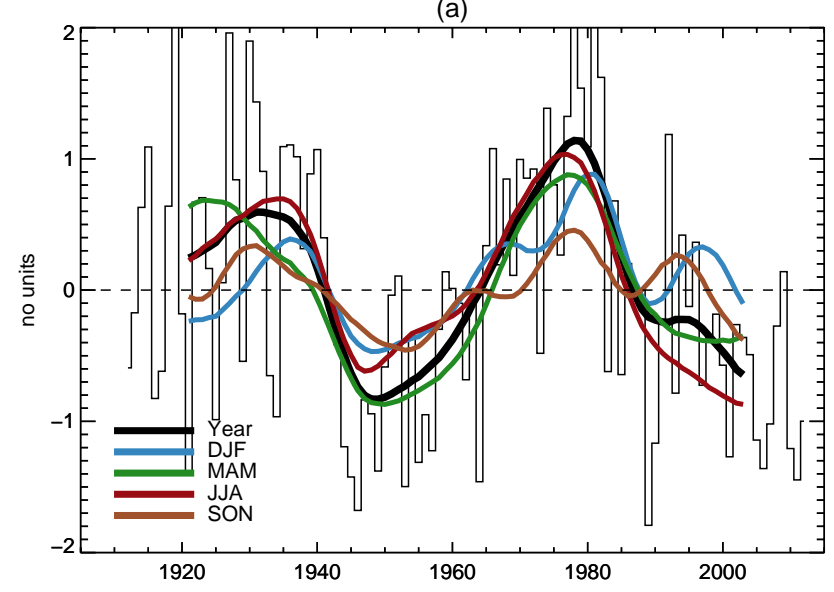

(b)

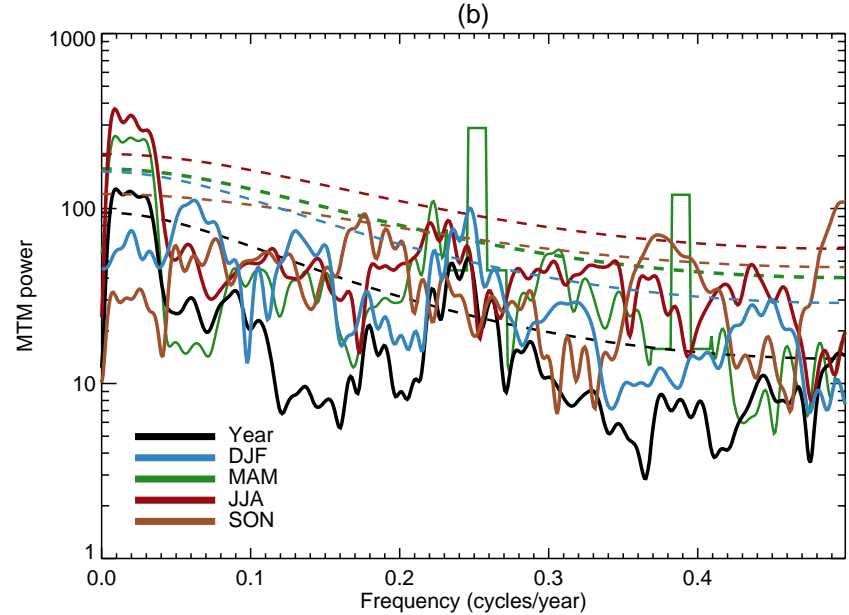

Fig. 2. (a) Standardized (undetrended) river flows of the Gave d'Ossau at Oloron-Sainte-Marie (Oloron-Ste-Croix). Bars: annual means. Thick lines: low-pass-filtered seasonal and annual series. (b) Multi-taper method (MTM) spectrum (Mann and Lees, 1996; Ghil et al., 2002) of seasonal and annual river flows of the Gave d'Ossau (thick line) and associated 0.05 significance level relative to the estimated noise background (dashed line). The Gave d'Ossau at Oloron-Sainte-Marie is shown in Fig. 1 with a larger triangle.

been extracted from the 20CR reanalysis, described in the previous subsection. Following Sutton and Dong (2012), a sea level pressure index, SLPI, is defined as the difference of averaged SLP for the region $35-60^{\circ} \mathrm{N}, 12^{\circ} \mathrm{W}-25^{\circ} \mathrm{E}$ and averaged SLP for the region $20-45^{\circ} \mathrm{N}, 40-12^{\circ} \mathrm{W}$. It corresponds to the pressure difference between western Europe and central eastern Atlantic.

In order to investigate the potential role of the AMV on large-scale circulation variations, the monthly HadSST3 sea surface temperature (SST) data set with a spatial resolution of $5^{\circ} \times 5^{\circ}$ (Kennedy et al., 2011a, b) from 1850 to 2012 is used. The AMV index is defined as the low-pass-filtered average of SST in the North Atlantic (in our case, the domain is $0-60^{\circ} \mathrm{N}, 75-7.5^{\circ} \mathrm{W}$ and the low-pass-filter used is the one described in Sect. 2.5) with the impact of anthropogenic temperature rise removed. A linear trend has commonly been used (e.g. Enfield et al., 2001; Knight et al., 2005) to estimate the anthropogenic temperature increase in this context. However the trend is not expected to be linear, especially for such a long period as the one studied here. The global average of SST is also commonly used as an estimator of the forced temperature rise (e.g. Trenberth and Shea, 2006). However, as there are initially very few observations outside the North Atlantic, the global average is expected to be biased towards the North Atlantic average at the beginning of the period. This procedure could therefore lead to an underestimation of the AMV variations at the beginning of the period. Here, a non-linear trend is estimated by linearly regressing the North Atlantic SST average of the observed (non-linear) $\mathrm{CO}_{2}$ concentration series in order to remove the impact of anthropogenic temperature rise. As is the case with others, this method has drawbacks, but tests we performed with the different methods described in this section have shown that the results presented in this study are not crucially dependent on the way the anthropogenic temperature rise is removed when computing the AMV index. By definition in the following, through the use of AMV we mean the detrended and low-pass-filtered AMV index.

\subsection{Hydrological model}

To investigate the role of land surface processes in river flow variations in summer, results of a hydrometeorological simulation over France for the period 1961-2012 are also analysed. This simulation is based on the SAFRAN-ISBAMODCOU (SIM) hydrometeorological coupled system. SIM is described and evaluated against observations in Habets et al. (2008). SIM is the combination of three independent systems. SAFRAN (Durand et al., 1993), based on observations, analyses the seven atmospheric variables at an hourly time step on an $8 \mathrm{~km}$ grid, which are necessary to force the soil-vegetation-atmosphere transfer (SVAT) scheme ISBA. Those variables are liquid and solid precipitation, incoming long-wave and short-wave radiation fluxes, $10 \mathrm{~m}$ wind speed, $2 \mathrm{~m}$ specific humidity and temperature. A description and elements of validation of SAFRAN are given in Quintana Segui et al. (2008) and Vidal et al. (2010). ISBA (Noilhan and Planton, 1989) computes the surface water and energy budgets, and then MODCOU (Ledoux et al., 1984) routes the surface runoff simulated by ISBA in the hydrographic network. Contrary to the other precipitation data sets used in this work and previously described, SAFRAN provides a high-resolution and adequate spatial estimation of precipitation over France for hydrological modelling (Quintana Segui et al., 2008; Vidal et al., 2010). However, SAFRAN does not cover the first half of the 20th century, mainly because of the poor spatial coverage of observations in France during this period. 
In this study, simulated river flows, evapotranspiration, runoff and the soil water index (SWI, the difference between the volumetric water content of the soil column and the wilting point divided by the difference between the field capacity and the wilting point) from SIM are analysed.

\subsection{Methods}

To extract the multi-decadal variations in the series analysed in this study, a 19-weight Hamming window low-pass filter is used. For yearly data, the half-amplitude point is about an $18 \mathrm{yr}$ period. Oscillations with a period of less than $9 \mathrm{yr}$ are virtually eliminated. In order to maintain the accuracy of the filtered series at the edges, no padding is applied: the first $9 \mathrm{yr}$ and last $9 \mathrm{yr}$ of the unfiltered series are considered as missing in the filtered series. The choice of the 19-weight Hamming window filter lies in our objective to isolate multidecadal variations from interannual noise without losing too many extreme points because of a larger window.

An important methodological issue for this study is whether or not the series should be detrended prior to the analyses. On the one hand, if multi-decadal variability exists in the variable of interest, there is a risk that the trend computed on raw data is itself spuriously created or influenced by the multi-decadal variations. Removing this trend from the original series would then generally lead to an underestimation of multi-decadal variability. On the other hand, if a real long-term trend exists in a variable of interest, for example a trend that could potentially be caused by anthropogenic forcing, not removing the trend would generally lead to an overestimation of multi-decadal variability. Moreover, and likely more importantly, a spurious relationship between two variables caused by long-term trends could exist and be erroneously attributed to multi-decadal variability. No perfectly satisfying solution to this issue exists. The risk of multidecadal variations interfering with the estimation of longterm trends is more or less serious depending on the length of the series. While the issue is major when dealing with short time series (relative to the period of oscillation, e.g. $40 \mathrm{yr}$ ), for longer series (e.g. $100 \mathrm{yr}$ long series), it is much less pronounced. Moreover, removal of a trend is expected to generally remain conservative, as it will tend to lead to an underestimation of multi-decadal variability rather than to an overestimation. As a consequence, we decided to remove the trends prior to most of the analyses described in this study when dealing with secular time series. In Sect. 5, where short hydrological simulations are analysed, results obtained with both detrended and undetrended series are shown, as it is not clear which approach is preferable in such a case.

A second related question is then what kind of trend should be removed. For the computation of the AMV, a non-linear trend has been used, as there is evidence (for example from climate modelling) that a linear trend is not the best model of the long-term anthropogenic influence on the average of SST in a large domain and over a long period. For hydroclimate variables over France, the signal-to-noise ratio being generally weaker, it is much less clear whether a non-linear model for trend should be preferred. As a result, linear trends have been used for all the variables considered in this study except for the computation of the AMV.

To assess the significance of correlations computed from the low-pass-filtered series, which exhibit a very high level of serial correlation, the test proposed by Ebisuzaki (1997) and applied in the same context by, for example, Enfield et al. (2001) is followed. The test is based on a Monte Carlo approach, with a randomization of phases in the frequency domain in order to generate random surrogate series with the same level of serial correlations than the original ones.

Through this paper, winter means December-JanuaryFebruary, spring means March-April-May, summer means June-July-August and autumn means September-OctoberNovember. Civil years, i.e. from January to December, are used.

\section{Multi-decadal variability in observed French hydroclimate}

\subsection{Hydroclimate variations}

The objective of this section is to characterize the multidecadal variations in French river flows and the potentially associated variations in surface climate. Simple visual inspection reveals important multi-decadal fluctuations in river flows for many of the gauging stations examined in this study, especially in spring. As an example, Fig. 2a shows that the Gave d'Ossau, a small river in southwestern France (see Fig. 1), exhibits large decadal variations in spring and annual river flows, clearly discernible even in unfiltered series. For this particular river, large decadal variations are also seen in summer. Decadal minimums in the 1950s and 2000s contrast with maximums in the 1920s and 1970s. Spectral analysis confirms that the Gave d'Ossau exhibits strong multi-decadal variations, significant for periods roughly greater than $30 \mathrm{yr}$ in spring and summer and for annual mean (Fig. 2b).

To quantify the importance of multi-decadal variations in river flows in France, the ratio of the standard deviation of low-pass-filtered and detrended series to the standard deviation of unfiltered and detrended series is shown for the seasonal and annual averages (Fig. 3a). The 25th, 50th, 75th and 95th percentiles of the same ratio computed for 10000 random white noise series of length equivalent to the ones of observed series are also shown in order to estimate the values of the ratio that can be obtained for series with no temporal autocorrelation.

Seasonally, for river flows, the importance of multidecadal variations relative to the total variability is generally much greater in spring. Large decadal variations are also seen in the annual series. For spring and annual series, the shift compared to the distribution of ratios obtained for white 

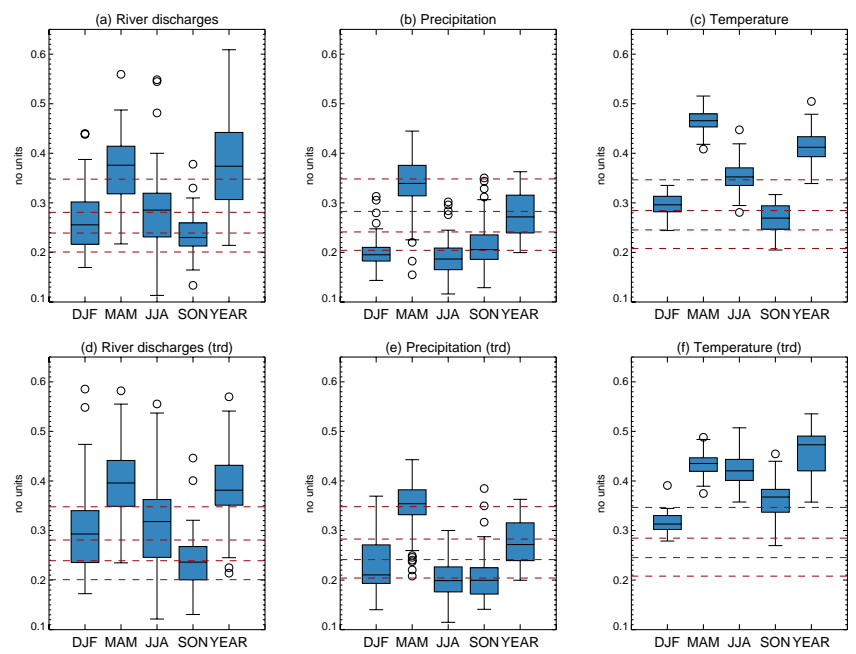

Fig. 3. Box plots of the ratio of the standard deviation of low-passfiltered seasonal and annual river flow series to the standard deviation of the corresponding unfiltered series at the different stations. The series have been linearly detrended prior to the analyses (the linear trend is computed for the longest possible period for each station). (a) River flows, (b) precipitation and (c) temperature. On the box plots, the 25th and 75th percentile and the median of the data, are shown by the lines. The whiskers are defined as the minimum and maximum values in the sample or by 1.5 times either the 25 th or 75 th percentile. In such a case, values greater than 1.5 times the 25 th or 75 th percentile are shown with a circle. The red dashed horizontal lines correspond to the 25th, 50th, 75th and 95th percentiles of equivalent ratios computed for 10000 random white noise series of length: $94 \mathrm{yr}$ for river flows (which corresponds to the median length of the river flow series), $101 \mathrm{yr}$ for precipitation and $107 \mathrm{yr}$ for temperature. (d) to (f) are the same as (a) to (c) except that the series have not been detrended.

noise is large, while it is small in winter and even more so in autumn. In summer, several stations exceed the ratios obtained with white noise. Note that as the standard deviation of unfiltered series is greater for spring averages than for yearly averages, in absolute terms, the multi-decadal signal is much larger in spring than for annual means (1.8 times larger on average over France, not shown).

A straightforward hypothesis to explain the multi-decadal variations in river flows is that they are driven by surface climate fluctuations. Figure $3 \mathrm{~b}$ shows that spring precipitation over France indeed also exhibits large multi-decadal fluctuations. Multi-decadal variations for the other seasons are much weaker and do not emerge from what is obtained for white noise. Interestingly, the magnitude of multi-decadal variations in river flows is generally greater than in precipitation. Indeed, the median over France of the ratio of multi-decadal standard deviation to interannual standard deviation is, for example, $0.28(0.25)$ in JJA (DJF) for river flows and only $0.19(0.20)$ for precipitation (Fig. 3). The same analysis is shown for temperature in Fig. 3c. The strongest ratios are seen in spring and annual means, as for river flows. Large values are also seen in summer.

To test the sensitivity of those results to the detrending step, the same analyses are shown for undetrended series (Fig. 3d-f). As expected, a shift towards larger values of the ratio is generally seen when the trends are not removed, especially for temperature. This is consistent with the fact that large trends exist in surface temperature. The shift is moderate for river flows, and very small for precipitation. Even if, as previously noted, the question of detrending is delicate, detrending the data seems to be more conservative, as previously argued, as it tends to lower the estimation of multidecadal variability.

The same temporal pattern as for the Gave d'Ossau, with a decadal minimum in the 1950s and maximums in the 1930s and 1980s is seen for many gauging stations in France, especially in spring (not shown), suggesting coherent variations in river flows on a large scale over France. This point is illustrated in Fig. 4, with the relative differences in detrended river flows between the 1938-1958 and 1965-1985 periods. The largest multi-decadal differences in river flows are generally seen in spring, with a signal shared by virtually all gauging stations over France. Differences in the $21 \mathrm{yr}$ average as large as or even greater than $40 \%$ are seen in spring between the two periods. Several stations also exhibit important multi-decadal differences in summer (especially over western France), and winter to a lesser extent, while the signal is generally weaker in autumn, except for a few stations. At the annual level, differences as large as $30 \%$ and greater than $25 \%$ are noted for most stations in western and central France. Corresponding precipitation and temperature anomalies between the two periods are also depicted in Fig. 4. The smaller spring river flows in the 1938-1958 period compared to the 1965-1985 period are associated with strong negative precipitation anomalies over France (up to $-30 \%$ ) and warmer temperature (up to $1 \mathrm{~K}$ ). No significant differences in temperature or precipitation are generally observed for the other seasons.

The 1938-1958 and 1965-1985 periods are not exceptional with regard to multi-decadal anomalies, as shown in Fig. 5; this figure shows, by means of box plots, the relative anomalies in river flows that correspond to all the decadal minimum and maximum seen for the Gave d'Ossau. The 1910-1930 period corresponds to positive river flow anomalies for the great majority of gauging stations except in winter, while the last period (1995 to present) is generally associated with negative anomalies. In this figure, both the results obtained for all the stations and with a subset of stations that excludes the ones identified as having strong influences (even only in low-flows; see Fig. 1) are shown. The differences remain modest, indicating that those strongly influenced stations are not responsible for the multi-decadal variations noted in the complete data set.

Multi-decadal fluctuations in river flows illustrated for the Gave d'Ossau in Fig. 2a in spring are therefore part of 

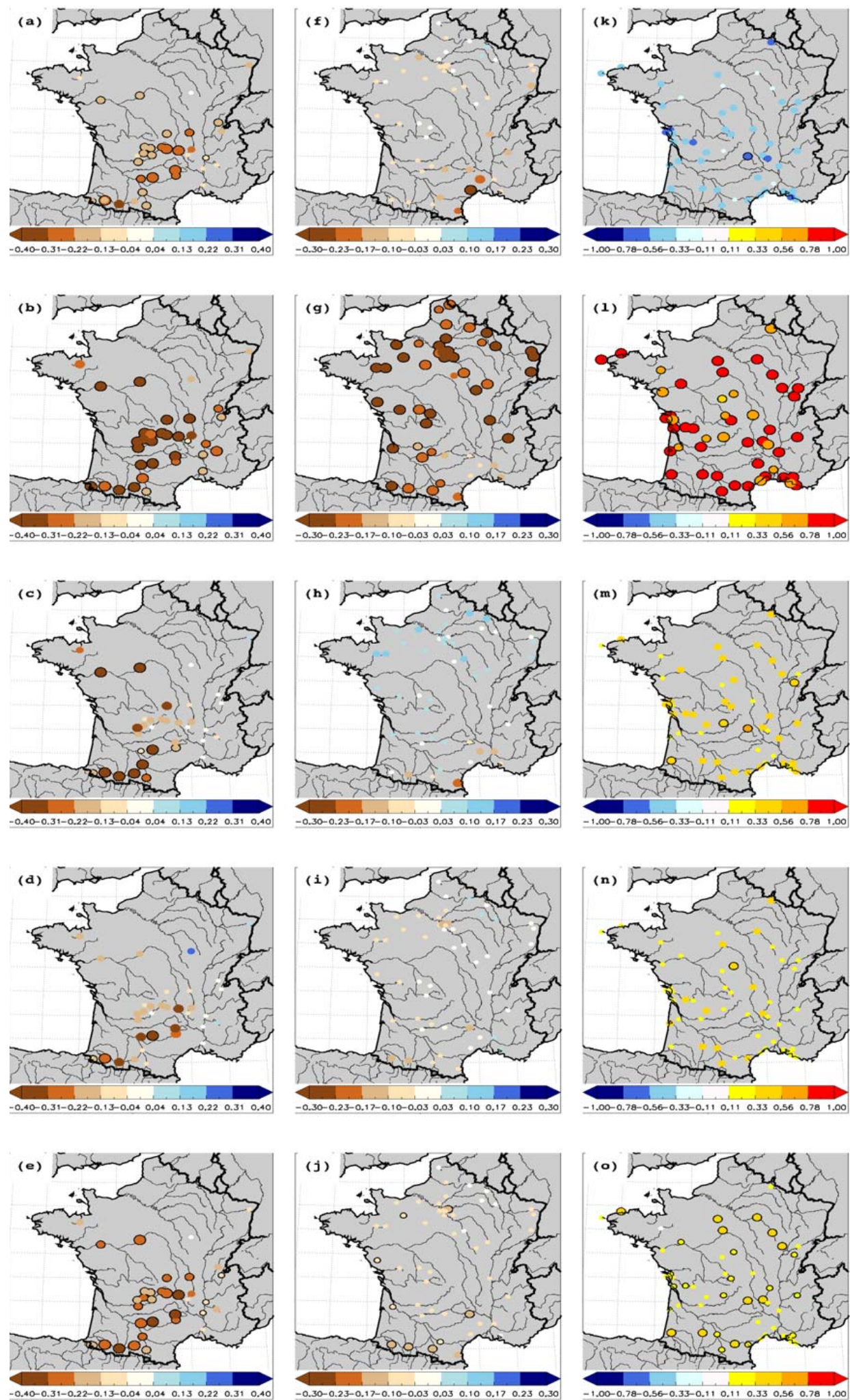

Fig. 4. Relative differences in detrended river flows between the 1938-1958 and 1965-1985 periods. The reference is the 1938-1985 average. (a) Winter, (b) spring, (c) summer, (d) autumn and (e) year. (f-j) Same as (a-e) but for detrended precipitation. (k-o) Differences in detrended temperature between the 1938-1958 and 1965-1985 periods. Black circles show where the differences are significant with $p<0.1$. Results for the Seine at Paris gauging station are missing in this graph as it ends in 1973. 

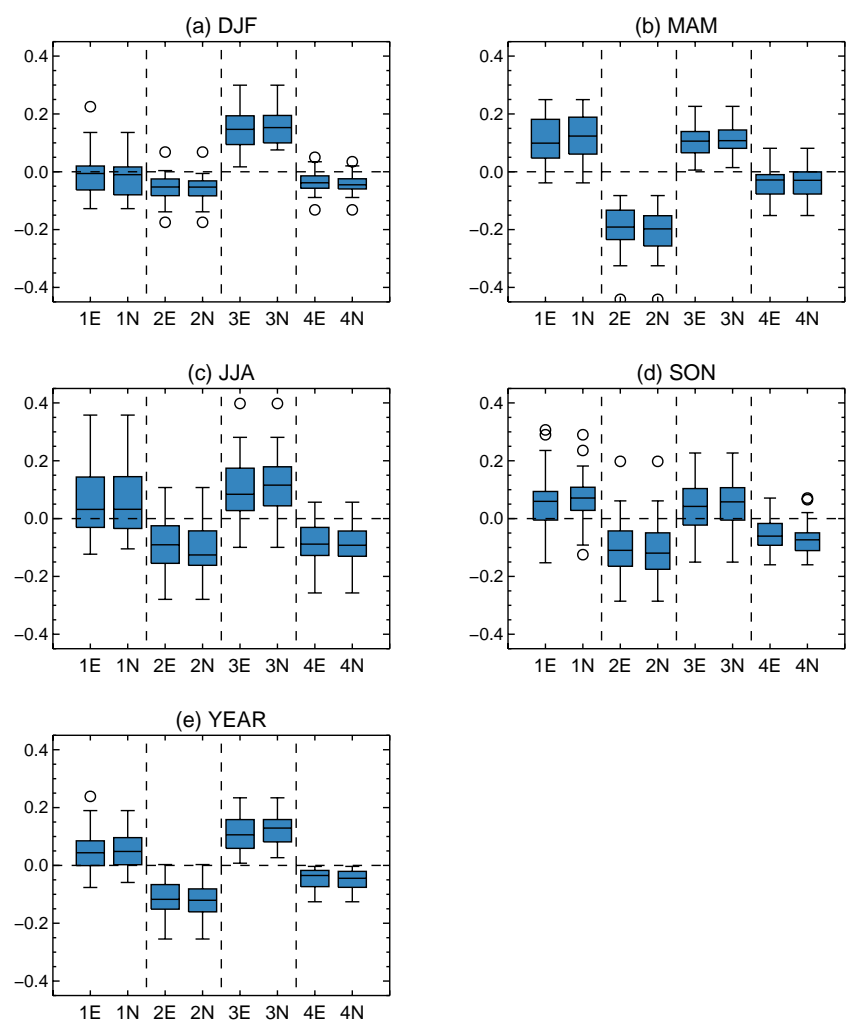

Fig. 5. Mean river flow anomalies relative to the average for the longest possible period for each station in four periods: 1910-1930 (1E and $1 \mathrm{~N}), 1938-1958$ (2E and $2 \mathrm{~N}), 1965-1985$ (3E and $3 \mathrm{~N}$ ) and 1995-2012 (4E and 4N) in (a) winter, (b) spring, (c) summer, (d) autumn and for (e) annual mean. The letter E means that all the stations are used and the letter $\mathrm{N}$ means that only the stations with no influence (see Fig. 1) are used. The series have been linearly detrended prior to the analyses (the linear trend is computed for the longest possible period for each station). In the box plots, the 25th and 75th percentile and the median of the data are shown by the lines. The whiskers are defined as the minimum and maximum values in the sample or by 1.5 times either the 25 th or 75 th percentile. In such a case, values greater than 1.5 times the 25 th or 75 th percentile are shown with a circle.

large-scale hydroclimate perturbations over France and are likely caused to a large extent by precipitation variations. An additional driver could be evapotranspiration. Indeed, as spring evapotranspiration in France is expected to be energylimited rather than water-limited (Boé, 2007), positive temperature anomalies at the interannual level in spring are expected to be associated with greater evapotranspiration. Following this line of reasoning, and supposing that this relation is still valid on multi-decadal timescales, larger temperatures in the period 1938-1958 would therefore be consistent with greater evapotranspiration, which would also result in smaller river flows. While multi-decadal variations in spring river flows could be explained by surface climate anomalies, the decadal differences in river flows observed in other seasons are more puzzling as they are not associated with significant specific precipitation anomalies.

\subsection{Link between multi-decadal variations in river flows and precipitation}

To assess whether multi-decadal variations in spring precipitation and river flows are in phase over the entire available periods, correlations are computed between detrended, low-pass-filtered spring precipitation averaged over France (GPCC data) and detrended, low-pass-filtered spring river flows at each gauging station (Fig. 6a). GPCC data are used here as they cover a longer period than HPS. The use of GPCC data is supported by the fact that on average over France, GPCC remains very close to our reference data set, HPS, for their common period as shown later in Fig. 7.

Very high significant correlations are obtained for the great majority of the gauging stations. Note that the average of precipitation over France is used here because the poor spatial sampling of HPS, the low resolution of GPCC and 20CR, and their potential inaccuracies at the grid cell level (see discussion in Sect. 2.2) make it impossible to robustly estimate precipitation for each river basins, which are often small, over the whole period of interest. It is not an important limitation to our study as the multi-decadal variations in spring precipitation over France are very spatially coherent, as shown in Fig. 6b. Except in southeastern France, precipitation at each point is indeed highly correlated with spatially averaged precipitation. Because of the orography, precipitation there is known to be often associated with particular synoptic conditions compared to the rest of France. Overall, this analysis shows that in spring it is justified to focus on spatially averaged precipitation over France in order to understand the bulk of river flow variations as the precipitation signal is large-scale.

Fig. $6 \mathrm{c}$ shows that there is also a high anti-correlation between low-pass-filtered and detrended temperature averaged in France and river flows in spring. As explained previously, this link could be a sign that multi-decadal variations in evapotranspiration also occur and influence river flows.

At this point, it is clear that at most gauging stations, river flows exhibit large multi-decadal variations in spring, probably due to a large extent to variations in precipitation. The potential causes of those variations in precipitation are investigated in the next section.

\section{Mechanisms of spring hydroclimate variations}

\subsection{Role of large-scale circulation}

Based on the previous analyses, and considering the straightforward physical link between precipitation and river flows, it appears highly likely that multi-decadal fluctuations in spring river flows are driven to a large extent by largescale precipitation variations over France. Assessing the 

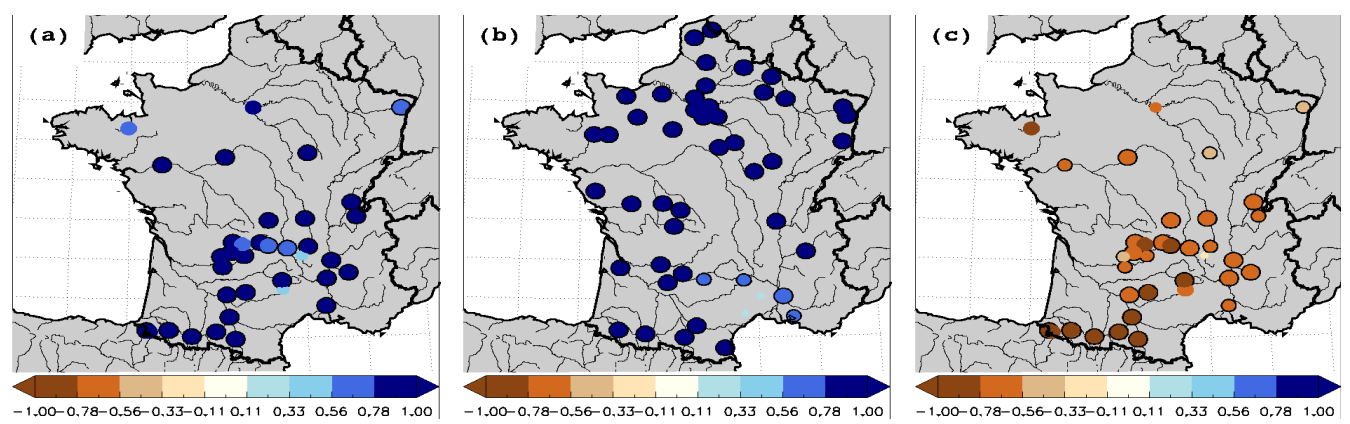

Fig. 6. (a) Correlation between low-pass-filtered spring precipitation averaged over France (GPCC data) and low-pass-filtered spring river flows at the different gauging stations. The correlation is computed for the longest possible period for each gauging station. (b) Correlation between low-pass-filtered spring precipitation averaged over France (GPCC data) and low-pass-filtered spring precipitation at each location (HPS data) for the 1910-1991 period. The use of different data sets for local precipitation and France average is intended to highlight the consistency of precipitation data sets. (c) Correlation between low-pass-filtered spring temperature averaged over France and low-passfiltered spring river flows at the different gauging stations. The correlation is computed for the longest possible period for each gauging station. Linear trends have been removed from the series prior to the analyses. Black circles show where the correlations are significant with $p<0.1$.
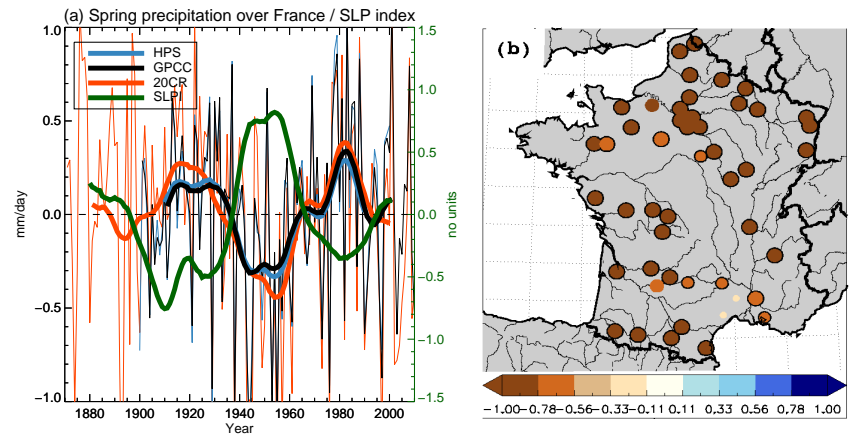

Fig. 7. (a) Average spring precipitation over France from three data sets (HPS, GPCC, 20CR) and standardized SLP index. The SLP index (SLPI) is defined as the difference of averaged SLP for the region $35-60^{\circ} \mathrm{N}, 12^{\circ} \mathrm{W}-25^{\circ} \mathrm{E}$ and averaged SLP for the region $20-45^{\circ} \mathrm{N}, 40-12^{\circ} \mathrm{W}$. The series have been linearly detrended (thin lines) and then low-pass-filtered (thick lines). The correlations between low-pass-filtered precipitation series (HPS, GPCC, 20CR) and SLPI in the respective maximum overlapping periods are -0.94 $(p<0.01),-0.89(p<0.01),-0.86(p<0.05)$. The correlations between low-pass-filtered precipitation series from the three data sets of the common 1910-1991 period are 0.99 (HPS/GPCC), 0.97 (HPS/20CR) and 0.96 (GPCC/20CR). (b) Correlation between lowpass-filtered and detrended SLPI index and precipitation at each location (HPS data). Black circles show where the correlations are significant with $p<0.1$.

robustness of the multi-decadal signal seen in spring precipitation and understanding its physical causes are therefore crucial.

Averaged and detrended precipitation over France in spring from three data sets (GPCC, HPS and 20CR) are depicted in Fig. 7a. Very similar multi-decadal signals are visible for all three data sets. GPCC and HPS data are not independent, as some stations used in GPCC are also used in
HPS. However, the statistical treatment of raw data for the two data sets is largely different. HPS is a priori more adapted to the study of low-frequency variations because of the homogenization procedure applied. The extremely small differences seen between multi-decadal precipitation variations in GPCC and HPS show the robustness of those features to the statistical pre-treatment of precipitation data and to the exact number and location of stations. Moreover, it shows that even if it is not homogenized, GPCC data can be used to estimate averaged precipitation over France, as it has the advantage of being available for a longer period compared to HPS.

Spring precipitation over France in 20CR exhibits a temporal pattern that is very similar to the one seen in HPS and GPCC, even if some limited differences exist, especially at the beginning of the record. This consistency with direct observations (GPCC, HPS) is noteworthy, as 20CR provides an indirect and completely independent estimation of precipitation. Indeed, no observed precipitation is used in 20CR. Note that SP observations, the only variable assimilated in 20CR, are much sparser in the early period of the reanalysis, which then has an impact on the quality of 20CR data (Compo et al., 2011). This likely explains to a large extent the limited discrepancies between 20CR and observed precipitation at the beginning of the 20th century. The fact that low-frequency variations in spring precipitation are well captured by $20 \mathrm{CR}$ also suggests that they may be largely driven by SLP.

The previous analysis shows that the large multi-decadal variations seen in spring precipitation over the 20th century are a robust feature of French climate. Indirectly, it also reinforces the confidence in the general robustness of multidecadal variations seen in spring river flows.

The multi-decadal variations in spring precipitation noted here are consistent with the results of Sutton and Dong (2012). Those authors also suggest that there is a link between the AMV and spring precipitation variations. In 


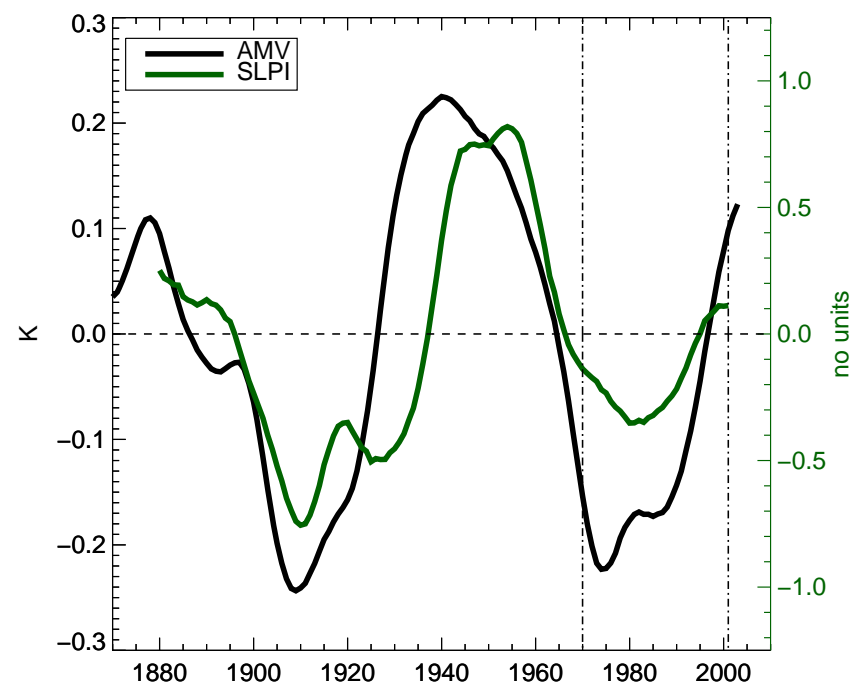

Fig. 8. Low-pass-filtered and detrended standardized SLPI and AMV index. The vertical lines delimit the period used for analyses described in Sect. 5.

spring, the positive phase of the AMV is associated with an anomalous ridge over western and central Europe, between two anomalous negative SLP anomalies over the eastern Atlantic and northeastern Europe (Sutton and Dong, 2012). This circulation pattern is expected to be associated with an increase in southerly flows over France, with an advection of warmer and drier air, and therefore generally with negative precipitation anomalies over France. Sutton and Dong (2012) define an SLP index to capture this potential impact of the AMV on atmospheric circulation on the North AtlanticEurope sector in spring. A similar SLP index (SLPI) is used in our study.

As shown in Fig. 7a, there is a very good anti-correlation between low-pass-filtered SLPI and precipitation anomalies over France in spring. High and significant anti-correlations with precipitation series between -0.86 and -0.94 depending on the precipitation data set (and therefore on the exact period) are noted. A positive value of SLPI corresponds to positive SLP anomalies over central/western Europe and negative anomalies over the eastern Atlantic and is associated, as physically expected, with negative precipitation anomalies over France. Figure 7b shows the correlation map between the low-pass-filtered and detrended SLPI index and HPS precipitation at each station in France in spring. The impact of SLPI on precipitation is large-scale and very consistent over France.

The previous result is strong evidence that the multidecadal variations in spring precipitation over France and therefore in river flows are driven by large-scale circulation.

\subsection{Role of the AMV}

Sutton and Dong (2012) suggest those large-scale circulation fluctuations are likely driven by the AMV. Figure 8 shows that there is indeed a strong covariability between the AMV and SLPI. However, this graph also suggests that the variations may not be exactly in phase. The AMV tends to lead SLPI; this is confirmed by Fig. 9a. Maximum correlations between the AMV and SLPI are found when the AMV leads SLPI by 5 or 6 yr. As expected a similar lag relationship with the AMV is found for spring precipitation (Fig. 8b). It can be seen in Fig. 8 that the lag tends to vary on the period as it seems to be generally larger at the beginning of the 20th century. Obviously, one must keep in mind that when dealing with multi-decadal variations, $130 \mathrm{yr}$ is a very short period with which to robustly estimate a potential small lag between two low-pass-filtered series. One must therefore remain cautious about the interpretation of this lag between AMV and SLPI or its variation. In any case, this lag remains consistent with the idea that the AMV drives SLPI variations (rather than the opposite). From a physical point of view, it is possible that the lag noted is due to the evolution of the exact spatial pattern of SST anomalies in the North Atlantic during the phase of the AMV as well as to the sensitivity of SLP to the precise SST pattern. Further work, based, for example, on dedicated numerical experiments with an atmospheric model forced by different SST patterns, would be needed to try to unambiguously demonstrate that the AMV is the driver of SLPI multi-decadal fluctuations and to better understand the physical mechanisms responsible for the potential lag. However, the success of this approach would lie in the capacity of GCMs to realistically capture the potential impact of the AMV on large-scale circulation, which is not necessarily granted.

Given the well-understood link between precipitation and river flows (Fig. 6a), and as multi-decadal precipitation variations are driven by SLPI, multi-decadal variations in SLPI generally explain a large part of multi-decadal variations in detrended spring river flows (Fig. 10b). Large anticorrelations with the annual mean are also generally noted.

Some significant correlations are also seen between SLPI (in spring) and river flows in summer or even in autumn; these are not straightforward to explain. Obviously, no synchronous relationship between atmospheric circulation in spring and river flows in summer is possible. This issue is examined in the next section.

Here at the end of this section, it can be concluded that multi-decadal variations in river flows in spring are very likely due to a large extent to variations in precipitation driven by large-scale circulation. Those multi-decadal variations in large-scale circulations are likely associated with an oceanic mode of multi-decadal variability, the AMV. 


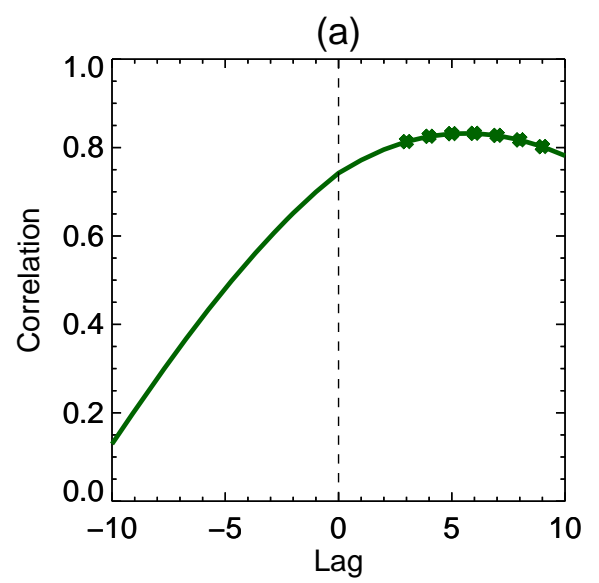

(b)

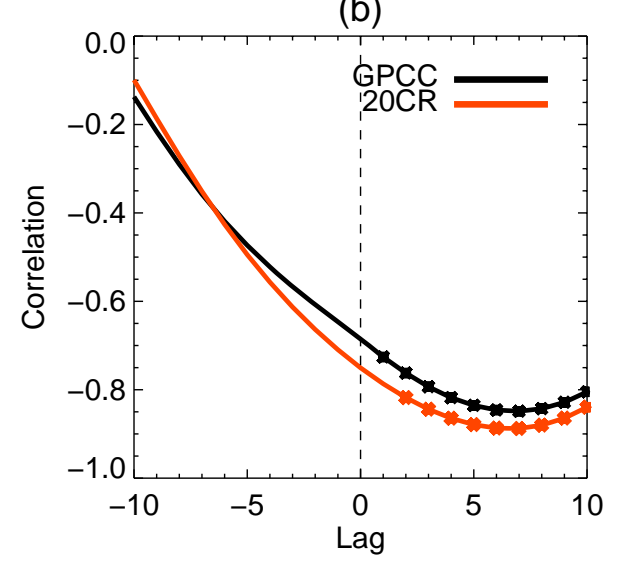

Fig. 9. Lag correlations between the AMV index and low-passfiltered and detrended (a) SLPI in spring, (b) averaged precipitation over France in spring (from GPCC and, in order to have a longer period, from 20CR) for different lags in years. Positive lags mean that the AMV leads. Crosses show where the correlations are significant with $p<0.1$.

\section{Summer variations: hydrometeorological simulations}

\subsection{Hypotheses}

Results from previous sections suggest that multi-decadal variations in river flows may exist in other seasons than spring, and most notably in summer. However, no physical explanation to support the existence of those potential signals has emerged, as multi-decadal variations in summer river flows are not directly associated with significant climate (i.e. precipitation and temperature) variations (Fig. 4 ).

If those variations in summer river flows are not synchronously caused by local climate anomalies, they might involve hydrological processes. Negative precipitation anomalies associated with positive SLPI in spring are expected to lead to drier soils. Moreover, as explained previously, a modulation of spring evapotranspiration could also be envisaged given the multi-decadal temperature variations noted
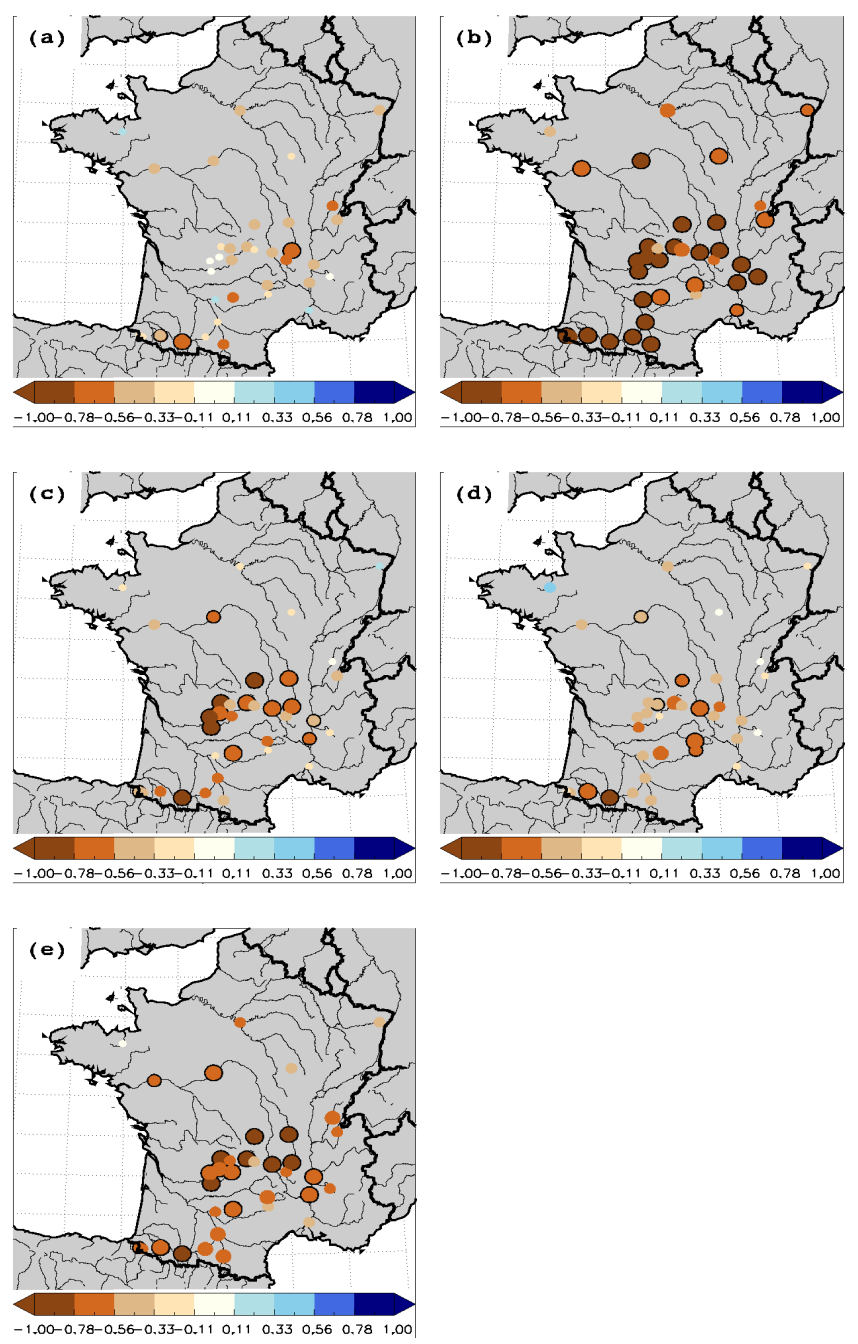

Fig. 10. Correlation between low-pass-filtered SLPI in spring and low-pass-filtered river flows at different gauging stations: (a) winter, (b) spring, (c) summer, (d) autumn and (e) year. The series have been linearly detrended prior to the analyses. Note that the correlations are computed for the longest possible period for each gauging station (and therefore not for the exact same period everywhere). Black circles show where the correlations are significant with $p<0.1$.

in Fig. 4. Positive SLPI anomalies would be associated with increased evapotranspiration in spring and therefore a decrease in soil moisture. The negative soil moisture anomalies associated with the variations in precipitation and evapotranspiration in spring might then persist until summer, and in turn impact river flows. Indeed, over drier soils, a smaller fraction of precipitation results in runoff and more water is stored in the soil or is lost as evapotranspiration in the end. An impact of spring precipitation and evapotranspiration on summer flows through a modulation of aquifer levels could also theoretically be possible. However, deep aquifers are not 
expected to play an important role in river flows for many of the stations analysed here (BRGM, 2006).

In this section, we focus on the possible bridge between spring climate variations and summer flows through a modulation of soil moisture. To study those mechanisms, knowledge of hydrological variables such as soil moisture and evapotranspiration is needed. Observations of those variables with a correct spatio-temporal sampling do not exist, and therefore one has to use hydrological modelling in that context. Here, the SIM system described in Sect. 2.4 is used.

The availability of the meteorological forcing limits the SIM hydrological simulation over France to the 1961-2012 period (and therefore limits the analyses to 1970-2003 when low-pass-filtered series are involved). This is obviously a very short period with which to study low-frequency variability. With such a short period it is particularly difficult to disentangle the impact of internal multi-decadal variations from the one of long-term trend that might, for example, be associated with increase in greenhouse gas (GHG) concentration, as discussed in Sect. 2.5. Also, for such a short sample of time, it is difficult to reach significance levels for statistical tests involving low-pass-filtered series. The objective of this section therefore remains modest: we want to evaluate the general plausibility of the mechanism previously described rather than unambiguously demonstrate its role. Note that as shown in Fig. 8, the period 1961-2012 mostly corresponds to a negative phase of the AMV, starting in the 1960s and ending in the 1990s. Over this period, SLPI follows a very similar temporal pattern.

First, spring, summer and annual simulated river flows by SIM are compared to observations, at the interannual level (1961-2012 period) and after low-pass filtering (1970-2003 period), in order to assess the ability of SIM to capture observed river flow variations (Fig. 11). For the vast majority of the stations studied here, the model captures the interannual variability in river flows well. Correlations lower than 0.70 are seldom found. Regarding low-frequency variations, the model also performs well, except at a few stations, especially in summer. It is not clear whether deficiencies in the hydrological model, direct anthropogenic influences on river flows or some measurement issues explain those poor correlations. Note that as SIM does not take into account direct human influence on river flows (dams, pumping, etc.) the fact that simulated river flows are most of the time consistent with observed river flows suggests that direct anthropogenic influences are not dominant in the interannual and multi-decadal fluctuations in the period simulated here for most stations. Note that a much more complete evaluation of SIM is given in Habets et al. (2008). As low-frequency variations in river flows are generally well simulated, and as the precipitation forcing is derived from observations, the previous analysis reinforces our confidence in the realism of low-frequency variations in the other components of the continental water cycle (evapotranspiration, SWI) simulated by SIM, which is strongly constrained by precipitation and river flows because

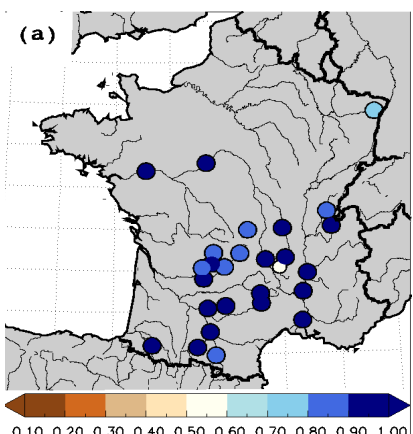

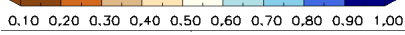

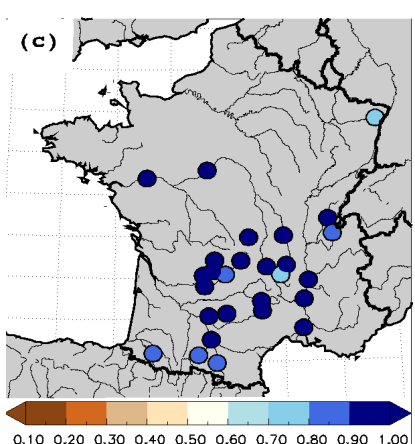

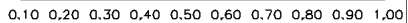
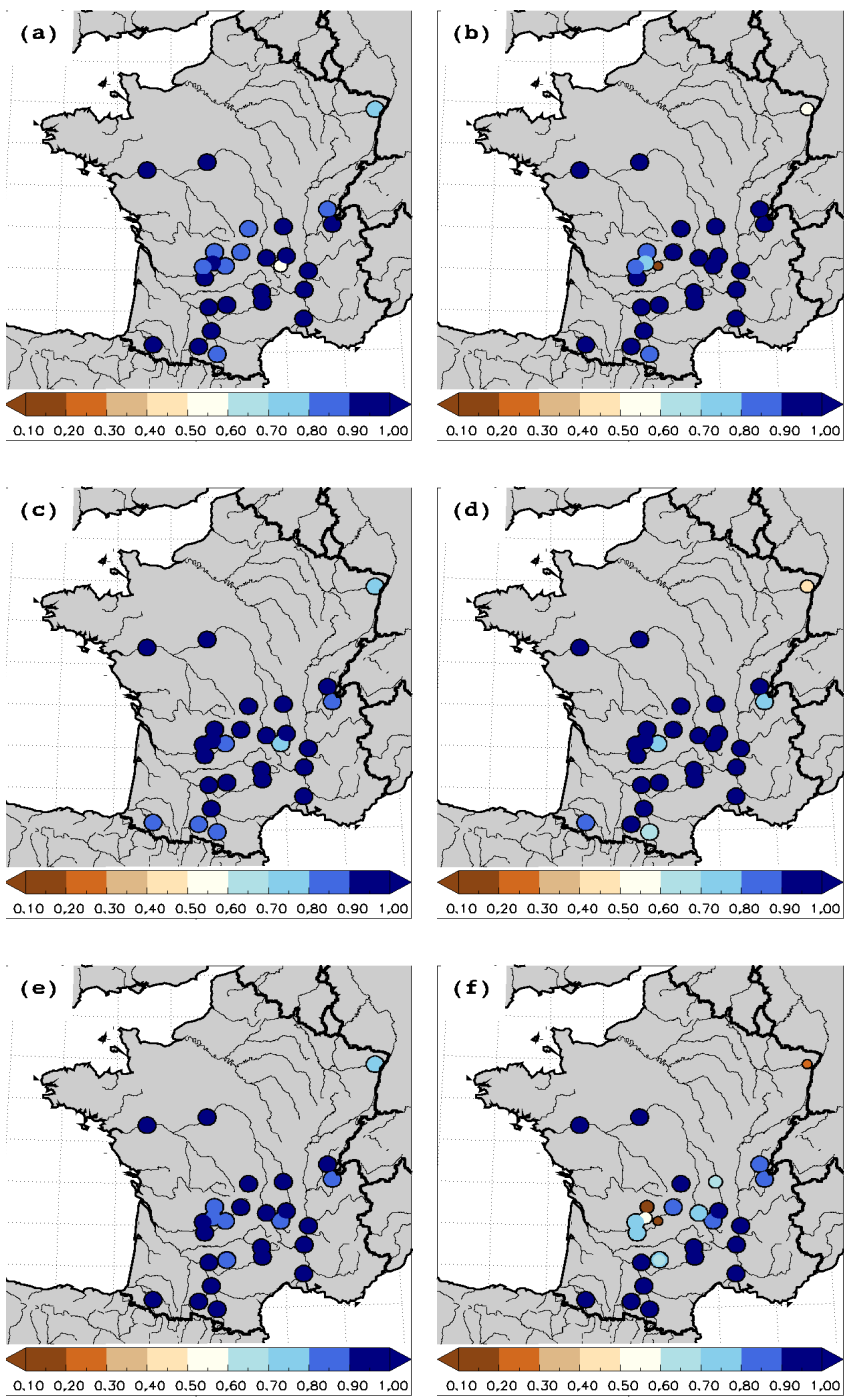

$\begin{array}{lllllllllllllllllllllll}0.10 & 0.20 & 0.30 & 0.40 & 0.50 & 0.60 & 0.70 & 0.80 & 0.90 & 1.00\end{array}$

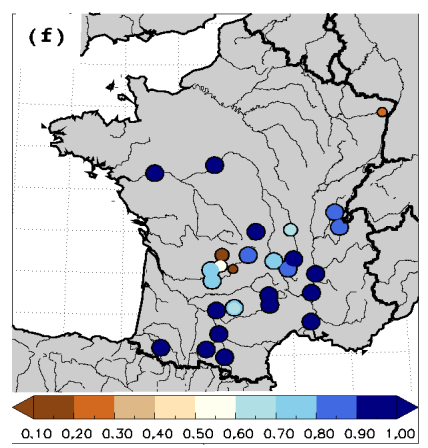

Fig. 11. Correlation between simulated and observed undetrended river flows, 1961-2012: (a) annual means, (c) spring and (e) summer. Correlation between low-pass-filtered and undetrended simulated and observed river flows, 1970-2003: (b) annual means, (d) spring and (f) summer. Some stations are missing compared to previous figures because of unavailability of simulated or observed data in the period of interest.

of water balance. However, this realism cannot be strictly demonstrated because of insufficient observations.

\subsection{Analysis}

The central element of the hypothesis tested in this section is that soil moisture at the end of spring can impact river flows in summer through a modification of the part of precipitation that contributes to runoff. Figure 12a shows the link between the soil wetness index (SWI) at the end of spring and the runoff-to-precipitation ratio simulated by SIM in summer for all the stations examined in this section, on 

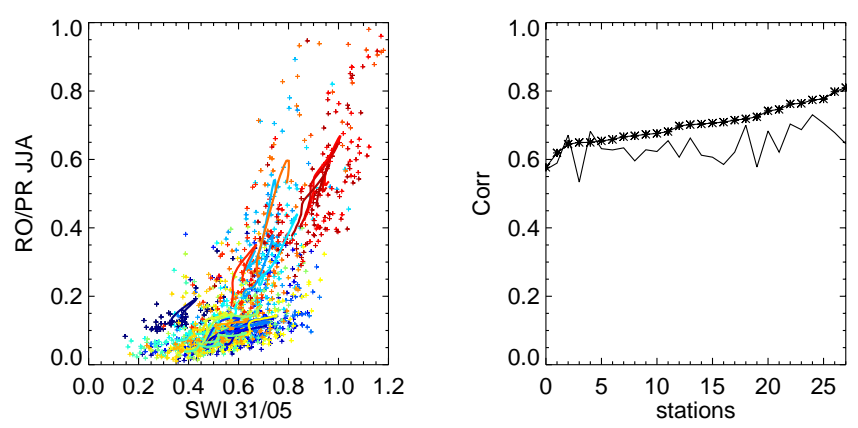

Fig. 12. (a) Runoff-to-precipitation ratio in JJA as a function of the SWI at the end of spring. (Runoff and SWI are simulated by SIM and precipitation comes from SAFRAN, the forcing of SIM.) Each colour corresponds to a simulated station of Fig. 11. The points are interannual values, while the lines correspond to low-pass-filtered data. (b) Spearman rank correlation between runoff-to-precipitation ratio in JJA and the SWI at the end of spring at the interannual level. The stars show the values for raw data and the line the values for detrended data. Stations have been ranked according to the correlation for raw data.

interannual and multi-decadal timescales. A clear non-linear relation exists. Dry soils in spring are associated with a very low runoff-to-precipitation ratio in summer, while for SWI at the end of spring close to 1 , most of the precipitation is transformed into runoff. To confirm the link between the SWI at the end of spring and the runoff-to-precipitation ratio in summer for each individual station, the rank correlations at the interannual level between those two quantities are shown in Fig. 12b. The impact of detrending is very limited, pointing towards the robustness of the relationship at the interannual level.

Now that it is clear that the basic mechanism is effective at the interannual level, multi-decadal variations in soil moisture at the end of spring are investigated. Results for both detrended and undetrended variables are shown for the following analyses as both approaches have important drawbacks when such a short period is studied (see discussion in Sect. 2).

First, the links between SLPI and spring evapotranspiration and soil moisture at the end of spring are studied. As previously hypothesized, positive SLPI is generally associated with greater evapotranspiration in spring. Because of lower precipitation and higher evapotranspiration, lower levels of soil moisture at the end of the spring are therefore also associated with positive SLPI (Fig. 13). Although detrending simulated data does have an impact and results in smaller absolute correlation, especially for soil moisture, the general picture remains the same. It has also been confirmed that there is a strong relationship between evapotranspiration in spring and soil moisture at the end of the spring (Fig. 14a and c). This is true whether the variables are detrended or not before computing the correlations. Note that using a singleday SWI (on 31 May), which may quickly answer to a spe-
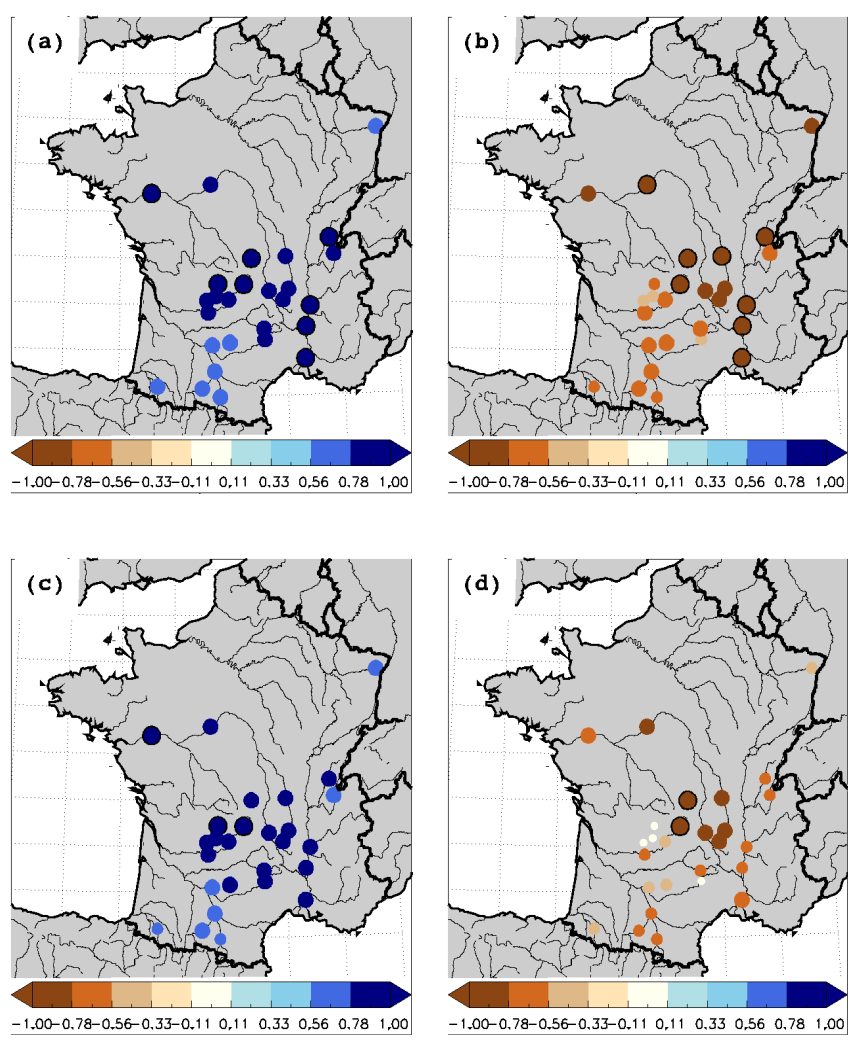

Fig. 13. Correlation between low-pass-filtered and detrended SLPI (the linear trend is computed for the 1871-2010 period) and lowpass-filtered simulated (a) evapotranspiration in spring and (b) soil wetness index at the end of spring (31 May). (c) and (d) are the same as (a) and (b) except that evapotranspiration in spring and soil wetness index at the end of spring (31 May) have been detrended. Black circles show where the correlations are significant with $p<$ 0.1 .

cific precipitation event, is not necessarily the best way to maximize the signal between SWI and SLPI or evapotranspiration in spring. However, we made this choice because the value of SWI in summer is physically more related to the value of SWI on 31 May than on any day before that, and it is therefore preferable for the next step of the analysis.

It is now tested as to whether soil moisture at the end of spring may have a non-negligible impact on summer flows on the multi-decadal timescale. Large positive correlations are seen for most stations between low-pass-filtered SWI at the end of spring and river flows in summer (Fig. 14). However, detrending the data has a large impact on the analysis for most of the stations in the Massif Central, while other stations maintain high correlations even after detrending. This is the case for the two stations of the Loire (the two northern stations in western France) and in southwestern France. Those are also stations where important multi-decadal variations in summer flows are observed (Fig. 4).

The results described in this section suggest that the AMV, through a modulation of SLPI, may also affect 

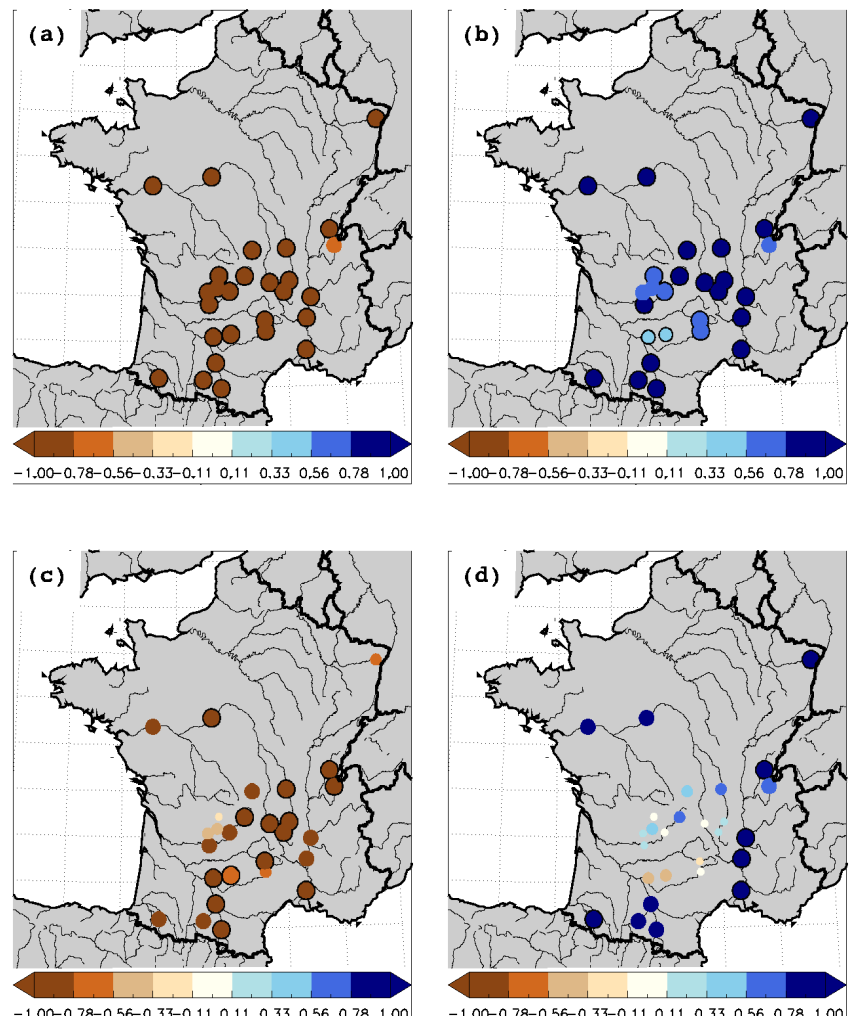

Fig. 14. (a) Correlation between low-pass-filtered simulated evapotranspiration in spring and soil wetness index at the end of spring (31 May). (b) Correlation between low-pass-filtered soil wetness index at the end of spring (31 May) and low-pass-filtered simulated summer river flows. (c) and (d) are the same as (a) and (b), respectively, except that all the variables have been detrended. Black circles show where the correlations are significant with $p<0.1$.

evapotranspiration over France in spring. Increased evapotranspiration and decreased precipitation lead to soil moisture depletion. Negative soil moisture anomalies in spring may lead to drier soils in summer because of soil moisture memory, with a potential influence on river flows in summer. This is a physically plausible mechanism, compatible with the decadal variations simulated at several stations in France in summer. However, for the majority of stations, the link between the SWI at the end of spring and summer flows is very dependent on the detrending step. As the trends may capture both the potential impact of GHG rise and internal multi-decadal variability in our short period of interest, it is difficult to reach strong conclusions for those stations.

Moreover, the situation is complicated by the fact that it is not impossible that sulfate aerosols have played a role in the multi-decadal variations of evapotranspiration in the second half of the 20th century and the beginning of the 21st century (Douville et al., 2012; Teuling et al., 2009). Contrary to GHG, sulfate aerosols are associated with negative anomalies in the surface radiation budget and therefore potentially in evapotranspiration. Superposed to the monotonic increase in GHG concentration, the multi-decadal variations in sulfate aerosols over France, with a transition from dimming to brightening in the early 1990s (Wild, 2012), could therefore have resulted in multi-decadal fluctuations in evapotranspiration somewhat in phase with SLPI and the AMV in the short period analysed in this section. The possibility cannot be excluded that the apparent correlations between SLPI and evapotranspiration over the period studied in this section could be partly coincidental and related to aerosol forcing.

The results described in this section should therefore be treated with great caution. Longer hydrological simulations over the entire 20th century would be needed to reach stronger conclusions. This would allow for better separation of multi-decadal variations from potential anthropogenic trends and not only relying on a short period potentially affected by external forcing on multi-decadal timescales.

\section{Discussion}

Large multi-decadal variations in river flows over France in the instrumental period have been described in this study. To fully grasp the importance of those multi-decadal variations, it is interesting to put them into the context of climate change. Boé et al. (2009) and Chauveau et al. (2013) give an estimate of the multi-model climate change signal projected in French river flows from an ensemble of CMIP3 models. In the middle of the 21st century (2046-2065 average), the ensemble mean change (which is generally seen as the "best estimate" of the climate change signal) over France is generally of the order of -15 to $-30 \%$ in spring and -25 to $-35 \%$ for yearly average. Figure 4 in this study therefore suggests that decadal differences might be as large or even greater than the climate change signal in the middle of the 21 st century in spring, and often not far from what is simulated at the annual level in the climate change context. If one supposes that observed multi-decadal variations mainly have an internal origin, internal low-frequency variability is therefore expected to be a very important actor in shaping the future evolution of river flows in France during the coming decades. If multi-decadal variations as large as the ones observed in the instrumental period can still happen in the climate of the future, and given the climate change signal estimated by past studies, multi-decadal variations could potentially temporarily reverse the long-term effect of global warming or strongly enhance the climate change signal, depending of its phasing. Note that as mentioned in the introduction, a debate currently exists regarding the nature of the AMV. If the AMV is not mainly a natural mode of variability (Booth et al., 2012), then there is no reason to expect it to continue in the future climate in the absence of adequate external forcing. Our interpretation is that the mainstream view is still that the AMV is largely an internal mode of variability (Zhang et al., 2013). 
It might seem somewhat surprising that such strong multidecadal hydroclimatic variations across France, and especially regarding river flows, have received little attention so far. The amplitude of multi-decadal variations is very seasondependent, and often much larger in spring, especially for precipitation and temperature. Studies have often focused preferentially on winter and summer, with a major exception being Sutton and Dong (2012), who have already described such multi-decadal variations in precipitation and temperature over France during spring and discussed their link with the AMV. Multi-decadal variations in precipitation extremes in Europe, including France, have also been described (Willems, 2013a, b). Regarding rivers flows over France, to the best of our knowledge, such large and widespread multidecadal variations have not been described before. The links between SST averaged in the North Atlantic (called AMO in those studies but probably best called the North Atlantic SST (NASST) index as those studies do not specifically deal with multi-decadal variations) and river flows in France have been studied by Oubeidillah et al. (2012) and Giuntoli et al. (2013). Other than at a few gauging stations, Oubeidillah et al. (2012) report no significant relationships between NASST and river flows in the Adour-Garonne Basin. Giuntoli et al. (2013) show significant relationships between hydrological drought severity at some gauging stations over France and the NASST index. The stronger signal is seen in southwestern France (including in the Adour-Garonne Basin), with negative correlations, which is generally consistent with what is seen in our study. A weaker signal is seen in northern France, with significant positive correlations there. Equivalent positive correlations are not seen in our study, but several reasons for that may exist. First, the spatial sampling in northern France of the long river flows series studied here is especially poor. Second, the NASST index studied by Giuntoli et al. (2013) includes both multi-decadal and interannual variations, and it is therefore not clear to what extent the link between drought severity and NASST is impacted by interannual timescales. Finally, the fact that we do not look at the same variables (mean river flow versus drought severity), period and season may also play a role.

The results described in this paper have some practical consequences. The existence of large multi-decadal variations in river flows has to be kept in mind when interpreting the results of trend analyses. In order to maintain correct spatial sampling, trend analyses often have to rely on relatively short time periods. Strong multi-decadal variations can seriously impact such short-term trends as noted by Hannaford et al. (2013) and Giuntoli et al. (2013), and therefore one has to remain cautious when attempting to attribute short-term trends. From a more applied perspective, it is clear that large multi-decadal variations in river flows may also have some practical implications, for example regarding hydropower production.

Note that some important caveats apply to the results described in this article. River flow data used are not homog- enized and we choose to use all available stations with long series to have the largest possible data set, even if some of them are known to be influenced by direct anthropogenic effects. If direct anthropogenic influences or measurement artefacts can artificially generate low-frequency variations in river flows locally, it is indeed unlikely for those artificial influences to be in phase over entire France. The largescale and very consistent signal that appears over France, especially in spring, suggests that the observed multi-decadal river flow variations are generally robust. Consistently with this idea, multi-decadal variations are noted even when the gauging stations with strong influences are excluded from the analyses (Fig. 5).

Moreover, it has been shown that multi-decadal variations in spring river flows are strongly associated with multidecadal variations in precipitation (and temperature) that are themselves driven by large-scale atmospheric circulation. High confidence can be attached to the existence of such multi-decadal variations in precipitation; these variations are very consistently seen in homogenized and unhomogenized precipitation data, and independently in precipitation from the 20CR reanalysis that does not assimilate precipitation observations.

The above are strong arguments to support the existence of large multi-decadal river flow variations in spring, and by extension in annual means. The same points cannot be made for the other seasons. Multi-decadal variations in winter, summer and autumn river flows are generally weaker, less spatially consistent and are not associated with strong surface climate variations. Even if a plausible mechanism has been proposed as a potential cause of those multi-decadal variations in summer, it has not been unambiguously demonstrated to be responsible for them.

Note also that as the SIM hydrological model does not take into account direct anthropogenic effects (e.g. impact of dams or extraction of water for irrigation) and as simulated flows are free of measurement errors, the consistency between simulated and observed river flows during the period for which the hydrological simulation exists is also an element that gives confidence in the reality and in the climatic causes of the variations seen in river flows, at least in the simulated period.

\section{Conclusions}

Multi-decadal variability in river flows over France in the instrumental period has been investigated. Multi-decadal variations in observed river flows have been noted. In general, those variations are clearly more important in spring (and, as a result, in annual means), and have been shown to be associated with multi-decadal variations in precipitation that are themselves driven by large-scale circulation. Those multidecadal variations in large-scale circulation can likely be 
interpreted as an atmospheric response to the SST anomalies associated with the AMV.

Although less important and less widespread than in spring, potential multi-decadal variations have also been noted in summer and winter for several stations. Those variations are not associated with specific large precipitation and temperature anomalies. It has been suggested that the summer variations could be associated with climate variations in spring through soil moisture memory: lower precipitation and greater evapotranspiration in spring would result in drier soils in summer, which would then lead to smaller river flows in summer. Those results are, however, based on a hydrological simulation, which is short in the context of multi-decadal variability, and are therefore subject to caution. Note also that locally, a modulation of snowmelt and/or the solid-toliquid precipitation ratio by the AMV could potentially exist and impact flows of nival rivers. Although such processes are taken into account in the hydrological modelling, this mechanism has not been investigated in our study.

Because soils tend to be well moistened (above field capacity) in winter, a comparable bridge from spring climate to the next winter through soil moisture memory is highly unlikely. Deep aquifers could play a similar role with potential longer memory, but this remains very hypothetical and in any case is not a good explanation for many stations in this study, as the impact of deep aquifers on flows is very small for many stations investigated here. The variations noted in winter, if real, therefore remain to be explained.

Progress therefore remains to be made in the characterization and understanding of multi-decadal river flow variations in France, especially in seasons other than spring. Long hydrological simulations of the whole 20th century and the early part of the 21 st century would be quite useful in that context. Such simulations would help to better characterize the multi-decadal variations in other components of the continental hydrological cycle (soil moisture, evapotranspiration, snow, aquifers) and in the end to understand how they impact river flows. Efforts to reconstruct the meteorological forcing over a long period are first necessary in order to do such hydrological simulation.

If one accepts that the AMV is mainly an internal mode of climate variability (Zhang et al., 2013), multi-decadal variations in river flows are expected to be mostly internal. They therefore have to be taken into account as potential uncertainties in climate change projections and in adaptation policies to climate change. As one cannot simply suppose that those variations will have the same amplitudes in the perturbed climate as in the instrumental period (the amplitude of low-frequency variations is not necessarily independent of the mean climate state, and additionally, $150 \mathrm{yr}$ at most is an extremely short period to estimate robustly the amplitude of multi-decadal variations) one has to rely on multiple members of climate projections to estimate those uncertainties. Even though current climate models might not be able to realistically capture the magnitude of low-frequency variations in the continental hydroclimate (Kavvada et al., 2013; or in the climate variables necessary to statistically or dynamically downscale climate models to force hydrological models), this point needs to be further investigated.

Because the multi-decadal variations in French river flows are likely due to internal climate variability, and especially since they are related to the AMV, one could hope to try to predict those variations thanks to decadal climate predictions (Goddard et al., 2013). However, the skill of current decadal predictions regarding continental variables such as precipitation and temperature is generally limited even for small lead times, but further work is also needed to better characterize the potential decadal predictability for river flows.

Acknowledgements. This work was supported by the French National Research Agency (ANR) in the framework of its JCJC programme (ECHO, decision no. ANR 2011 JS56 014 01). The authors thank Laurent Terray, Christophe Cassou and Yohan Ruprich-Robert for useful discussions about this work. The authors also acknowledge Météo-France (Direction de la climatologie) for providing the homogenized precipitation and temperature data sets, and Eric Martin for providing the SAFRAN-ISA-MODCOU data. Support for the Twentieth Century Reanalysis Project data set is provided by the US Department of Energy, Office of Science, Innovative and Novel Computational Impact on Theory and Experiment (DOE INCITE) programme; by the Office of Biological and Environmental Research (BER); and by the National Oceanic and Atmospheric Administration Climate Program Office. Finally, the authors are grateful to Benjamin Graff (Compagnie Nationale du Rhône), Pierre Boulestreau (Société Hydro-Electrique du Midi) and Hugues Haeffner (GDF SUEZ) for the initial scientific question that motivated this work and for useful discussions. The authors thank the two anonymous reviewers for their insightful comments, which greatly helped to improve the manuscript.

Edited by: A. Gelfan

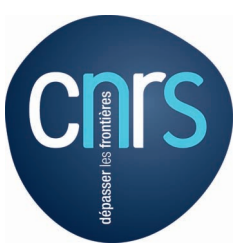

The publication of this article is financed by CNRS-INSU.

\section{References}

Boé, J., Terray, L., Martin, E., and Habets, F.: Projected changes in components of the hydrological cycle in French river basins during the 21 st century, Water Resour. Res., 45, W08426, doi:10.1029/2008WR007437, 2009.

Booth, B. B. B., Dunstone, N. J., Halloran, P. R., Andrews, T., and Bellouin, N.: Aerosols implicated as a prime driver of twentiethcentury North Atlantic climate variability, Nature, 484, 228-232, 2012.

BRGM: Aquifères et eaux souterraines de France, édition BRGM, ref: STC003, Orléans, France, 2006. 
Chauveau, M., Chazot, S., Perrin, C., Bourgin, P.-Y., Sauquet, E., Vidal, J.-P., Rouchy, N., Martin, E., David, J., Norotte, T., Maugis, P., and de Lacaze, X.: Quels impacts des changements climatiques sur les eaux de surface en France à l'horizon 2070?, La Houille Blanche, 4, 5-15, 2013.

Compo, G. P., Whitaker, J. S., Sardeshmukh, P. D., Matsui, N., Allan, R. J., Yin, X., Gleason, B. E., Vose, R. S., Rutledge, G., Bessemoulin, P., Brönnimann, S., Brunet, M., Crouthamel, R. I., Grant, A. N., Groisman, P. Y., Jones, P. D., Kruk, M., Kruger, A. C., Marshall, G. J., Maugeri, M., Mok, H. Y., Nordli, Ø., Ross, T. F., Trigo, R. M., Wang, X. L., Woodruff, S. D., and Worley, S. J.: The twentieth century reanalysis project, Q. J. Roy. Meteor. Soc., 137, 1-28, 2011.

Delworth, T. L. and Mann, M. E.: Observed and simulated multidecadal variability in the Northern Hemisphere, Clim. Dynam., 16, 661-676, 2000.

Deser, C., Phillips, A. S., Bourdette, V., and Teng, H.: Uncertainty in climate change projections: the role of internal variability, Clim. Dynam., 38, 527-546, 2010.

Deser, C., Knutti, R., Solomon, S., and Phillips, A. S.: Communication of the role of natural variability in future North American climate, Nat. Clim. Change, 2, 775-779, 2012.

Douville, H., Decharme, B., Ribes, A., Alkama, R., and Sheffield, J.: Anthropogenic influence on multi-decadal changes in reconstructed global evapotranspiration, Nat. Clim. Change, 3, 59-62, 2012.

Durand, Y., Brun, E., Merindol, L., Guyomarc'h, G., Lesaffre, B., and Martin, E.: A meteorological estimation of relevant parameters for snow schemes used with atmospheric models, Ann. Glaciol., 18, 65-71, 1993.

Ebisuzaki, W.: A method to estimate the statistical significance of a correlation when the data are serially correlated, J. Climate, 10, 2147-2153, 1997.

Enfield, D. B., Mestas-Nunez, A. M., and Trimble, P. J.: The Atlantic multidecadal oscillation and its relation to rainfall and river flows in the continental US, Geophys. Res. Lett., 28, 2077-2080, 2001.

Ghil, M., Allen, R. M., Dettinger, M. D., Ide, K., Kondrashov, D., Mann, M. E., Robertson, A., Saunders, A., Tian, Y., Varadi, F., and Yiou, P.: Advanced spectral methods for climatic time series, Rev. Geophys., 40, 3.1-3.41, 2002.

Giuntoli, I., Renard, B., Vidal, J.-P., and Bard, A.: Low flows in France and their relationship to large-scale climate indices, J. Hydrol., 482, 105-118, 2013.

Goddard, L. Kumar, A., Solomon, A., Smith, D., Boer, G., Gonzalez, P., Kharin, V., Merryfield, W., Deser, C., Mason, S. J., Kirtman B. P., Msadek, R., Sutton, R., Hawkins, E., Fricker, T., Hegerl, G., Ferro, C. A. T., Stephenson, D. B., Meehl, G. A., Stockdale, T., Burgman, R., Greene A. M., Kushnir, Y., Newman, M., Carton, J., Fukumori, I., and Delworth, T.: A verification framework for interannnual-to-decadal prediction experiments, Clim. Dynam., 40, 245-272, 2013.

Gray, S. T., Graumlich, L. J., Betancourt, J. L., and Pederson, G. T.: A tree-ring based reconstruction of the Atlantic Multidecadal Oscillation since 1567 A.D., Geophys. Res. Lett., 31, L12205, doi:10.1029/2004GL019932, 2004.
Habets, F., Boone, A., Champeaux, J.-L., Etchevers, P., Franchisteguy, L., Leblois, E., Ledoux, E., Le Moigne, P., Martin, E., Morel, S., Noilhan, J., Quintana Segui, P., Rousset-Regimbeau, F., and Viennot, P.: The SAFRAN-ISBA-MODCOU hydrometeorological model applied over France, J. Geophys. Res., 113, D06113, doi:10.1029/2007JD008548, 2008.

Hannaford, J., Buys, G., Stahl, K., and Tallaksen, L. M.: The influence of decadal-scale variability on trends in long European streamflow records, Hydrol. Earth Syst. Sci., 17, 2717-2733, doi:10.5194/hess-17-2717-2013, 2013.

Hawkins, E. and Sutton, R.: The potential to narrow uncertainty in regional climate prediction, B. Am. Meteorol. Soc., 90, 10951107, 2009.

Kavvada, A., Ruiz-Barradas, A., and Nigam, S.: AMO's structure and climate footprint in observations and IPCC AR5 climate simulations, Clim. Dynam., 41, 1345-1364, doi:10.1007/s00382013-1712-1, 2013.

Kennedy, J. J., Rayner, N. A., Smith, R. O., Saunby, M., and Parker, D. E.: Reassessing biases and other uncertainties in sea-surface temperature observations since 1850 part 1: measurement and sampling errors, J. Geophys. Res., 116, D14103, doi:10.1029/2010JD015218, 2011a.

Kennedy, J. J., Rayner, N. A., Smith, R. O., Saunby, M., and Parker, D. E.: Reassessing biases and other uncertainties in sea-surface temperature observations since 1850 part 2: biases and homogenisation, J. Geophys. Res., 116, D14104, doi:10.1029/2010JD015220, 2011b.

Kerr, R. A.: A North Atlantic climate pacemaker for the centuries, Science, 288, 1984-1985, 2000.

Knight, J. R., Allan, R. J., Folland, C. K., Vellinga, M., and Mann, M. E.: A signature of persistent natural thermohaline circulation cycles in observed climate, Geophys. Res. Lett., 32, L20708, doi:10.1029/2005GL024233, 2005.

Krueger, O., Schenk, F., Feser, F., and Weisse, R.: Inconsistencies between long-term trends in storminess derived from the 20CR reanalysis and observations, J. Climate, 26, 868-874, 2013.

Ledoux, E., Girard, G., and Villeneuve, J. P.: Proposition d'un modèle couplé pour la simulation conjointe des écoulements de surface et des écoulements souterrains sur un bassin hydrologique, La Houille Blanche, 1, 101-110, 1984.

Otterå, O. H., Bentsen, M., Drange, H., and Suo, L.: External forcing as a metronome for Atlantic multidecadal variability, Nat. Geosci., 3, 688-694, 2010.

Oubeidillah, A. A., Tootle, G., and Anderson, S.-R.: Atlantic Ocean sea-surface temperatures and regional streamflow variability in the Adour-Garonne basin, France, Hydrol. Sci. J., 57, 496-506, 2012.

Quintana Segui, P., Le Moigne, P., Durand, Y., Martin, E., Habets, F., Baillon, M., Franchisteguy, L., Morel, S., and Noilhan, J.: Analysis of near-surface atmospheric variables: validation of the SAFRAN analysis over France, J. Appl. Meteorol. Climatol., 47, 92-107, 2008.

Mann, M. E. and Lees, J. M.: Robust estimation of background noise and signal detection in climatic time series, Clim. Change, 33, 409-445, 1996.

Moisselin, J. M., Schneider, M., Canellas, C., and Mestre, O.: Changements climatiques en France au XXeme siecle. Etude des longues series de donnees homogeneisees francaises de precipitations et temperatures, Meteorol., 38, 45-56, 2002. 
Noilhan, J. and Planton, S.: A simple parametrization of land surface processes for meteorological models, Mon. Weather Rev., 117, 536-549, 1989.

Rudolf, B. and Schneider, U.: Calculation of gridded precipitation data for the global land-surface using in-situ gauge observations, in: Proceedings of the 2nd Workshop of the International Precipitation Working Group IPWG, Monterey, October 2004, EUMETSAT, ISBN 92-9110-070-6, ISSN 1727-432X, 231-247, 2005.

Schlesinger, M. E. and Ramankutty, N.: An oscillation in the global climate system of period 65-70 years, Nature, 367, 723-726, 1994.

Sutton, R. T. and Dong, B.: Atlantic Ocean influence on a shift in European climate in the 1990s, Nat. Geosci., 5, 788-792, 2012.

Sutton, R. T. and Hodson, D. L. R.: Atlantic Ocean forcing of North American and European summer climate, Science, 309, 115118, 2005.

Terray, L. and Boé, J.: Quantifying 21st-century France climate change and related uncertainties, C. R. Geosci., 345, 136-149, 2013.
Trenberth, K. E. and Shea, D. J.: Atlantic hurricanes and natural variability in 2005, Geophys. Res. Lett., 33, L12704, doi:10.1029/2006GL026894, 2006.

Vidal, J.-P., Martin, E., Franchistéguy, L., Baillon, M., and Soubeyroux, J.-M.: A 50-year high-resolution atmospheric reanalysis over France with the Safran system, Inter. J. Climate, 30, 16271644, 2010.

Wild, M.: Enlightening global dimming and brightening, B. Am. Meteorol. Soc., 93, 27-37, 2012.

Willems, P.: Multidecadal oscillatory behavior of rainfall extremes in Europe, Clim. Change, 120, 931-944, 2013a.

Willems, P.: Adjustment of extreme rainfall statistics accounting for multidecadal climate oscillations, J. Hydrol., 490, 126-133, 2013b.

Zhang, R., Delworth, T. L., Sutton, R., Hodson, D. L., Dixon, K. W., Held, I. M., Kushnir, Y., Marshall, J., Ming, Y., Msadek, R., Robson, J., Rosati, A. J., Ting, M., and Vecchi, G. A.: Have aerosols caused the observed Atlantic Multidecadal Variability? J. Atmos. Sci., 70, 1135-1144, 2013. 